\title{
Effect of nifedipine on cystometry-induced elevation of blood pressure in patients with a reflex urinary bladder after a high level spinal cord injury
}

\author{
M Thyberg MD , ${ }^{1}$ P Ertzgaard MD,${ }^{1} \mathrm{M}$ Gylling RN, ${ }^{1}$ G Granerus MD PhD ${ }^{2}$ \\ ${ }^{1}$ Spinal Cord Unit, Department of Rehabilitation Medicine, ${ }^{2}$ Department of Clinical \\ Physiology, Faculty of Health Sciences, Linköping University Hospital, S-581 85 \\ Linköping, Sweden.
}

In 10 patients with a reflex urinary bladder after a cervical or high thoracic spinal cord injury, the effect of nifedipine on the cystometry-induced elevation of blood pressure was studied. The blood pressure was measured every $30 \mathrm{~s}$ in four consecutive cystometries before and after administration of $10 \mathrm{mg}$ nifedipine sublingually. In each patient there was a decrease in the maximum systolic and diastolic blood pressure after the administration of nifedipine. In the whole group the mean maximum systolic pressure decreased significantly from $147 \mathrm{mmHg}$ (range $119-165, \mathrm{SD} 14$ ) to $118 \mathrm{mmHg}$ (range 99-145, SD 14). The mean maximum diastolic pressure decreased from $110 \mathrm{mmHg}$ (range 96-124, SD 10) to $83 \mathrm{mmHg}$ (range $71-99, \mathrm{SD} 10$ ). The effect of nifedipine was significant in each of the four cystometries that were performed. The decrease in blood pressure was due to both a significant decrease of the baseline pressure and a significant decrease of the blood pressure reaction during cystometry. Nifedipine may be useful in order to prevent dangerous blood pressure reactions, e.g. during cystoscopy and other diagnostic or therapeutic procedures in spinal cord injured patients with autonomic dysreflexia.

Keywords: blood pressure; neuropathic bladder; nifedipine; spinal cord injuries; urodynamics; autonomic dysreflexia.

\section{Introduction}

A sudden uninhibited reflex elevation of blood pressure is a well recognised and sometimes serious problem in patients with a spinal cord injury above the fifth thoracic level. ${ }^{1}$ Attacks are induced by stimuli below the level of the lesion, most often from the urinary bladder. Stimulation of the urinary bladder has also been used in order to evaluate the effect of pharmacological prevention and treatment of blood pressure elevation, and among other substances the calcium channel blocking agent nifedipine has been tried. Sublingual administration of nifedipine seems to be effective in the prevention of an expected attack, eg during cystoscopy, but methodological problems, like small numbers of comparable measurements, lack of standardised stimuli and unspecified intervals of blood pressure measurement make the interpretation of previous studies difficult. ${ }^{2-5}$ We have previ- ously described the blood pressure response in repeated cystometries, ${ }^{5}$ and the aim of this study was to evaluate the effect of nifedipine with this improved technique.

\section{Patients}

Ten patients with a spinal cord injury above the fifth thoracic segment were included. The neurological functional level and classification according to Frankel is shown in Table I. All patients who were classified as Frankel B had an anterior cord syndrome. The patient who was classified as Frankel C had some touch sensation in his feet and some voluntary flexion of his toes. All patients had a reflex urinary bladder, according to Lapides' classification, with neither sensation for filling nor voluntary control of the bladder on clinical examination and cystometry. All patients had experienced some symptoms of autonomic 
Table I Neurological functional level and classification according to Frankel

\begin{tabular}{lccccccccccc}
\hline & \multicolumn{10}{c}{ Patients } \\
\cline { 2 - 12 } & 1 & 2 & 3 & 4 & 5 & 6 & 7 & 8 & 9 & 10 \\
\hline Level & C5 & C4 & C8 & C7 & C6 & C6 & T3 & C6 & C5 & C7 \\
Frankel grade & B & A & B & A & A & A & B & C & A & B \\
\hline
\end{tabular}

dysreflexia and also a reflex blood pressure elevation had been demonstrated during cystometry. All patients were male with ages ranging from 16 to 53, and a median of 24. The post lesion time ranged from 0.5 to 16 years, with a median of 4 years. No additional disease was known in the group of patients and there was no other medication with known or suspected effect on blood pressure, except a daily dose of $150 \mathrm{mg}$ baclofen in one patient.

\section{Methods}

The blood pressure was measured every $30 \mathrm{~s}$ during a series of four consecutive cystometries before and four consecutive cystometries after administration of $10 \mathrm{mg}$ nifedipine sublingually. In this study, one cystometry is defined as measurement of the detrusor pressure during one filling phase and the following detrusor contraction, ie the emptying phase. $^{5}$

The systolic and diastolic blood pressure was measured in the left arm with a $12 \mathrm{~cm}$ cuff, a mercury column and auscultation of the Korotkoff sounds. ${ }^{5}$ In order to perform the repeated measurements in a convenient way, the cuff valve was connected to compressed air, making it possible to fill the cuff quickly. The systolic pressure was defined as the pressure at which the first sound was heard. The diastolic pressure was defined as the pressure at which the last sound was heard (phase V). The blood pressure measurements were rounded to the nearest $5 \mathrm{mmHg}$. The blood pressure was measured during both the filling and emptying phases and also during $3 \mathrm{~min}$ after the contraction of the bladder. At each cystometry there were also 3 consecutive measurements at rest, before the filling started. The mean systolic and the mean diastolic pressure from these three measurements was called the baseline blood pressure. The difference between the maximum blood pressure recorded and the baseline blood pressure, in each cystometry, was called the blood pressure reaction.

The heart rate was measured by auscultation of the heart during $1 \mathrm{~min}$ before each filling of the bladder. In most of the patients, the heart rate was not measured during the filling and emptying phases of the cystometries.

Cystometries were performed with a suprapubic technique that has been described in previous methodological studies. $^{5-7}$ There is no systematic change of the detrusor or blood pressures of consecutive cystometries with 10 min intervals. ${ }^{5,7}$ A filling rate of $50 \mathrm{ml} / \mathrm{min}$ with $37^{\circ} \mathrm{C}$ normal saline was used. Filling was stopped as soon as a detrusor contraction was observed and the detrusor pressure exceeded $2 \mathrm{kPa}$. The interval between the end of one cystometry and the start of the next one was about $10 \mathrm{~min}$. After four cystometries, $10 \mathrm{mg} \mathrm{ni}-$ fedipine was given sublingually and the second series of cystometries was started 10 min later.

Wilcoxon's signed rank test was used to test differences.

\section{Results}

\section{Blood pressure}

In each patient there was a decrease of the maximum blood pressure after administration of nifedipine (Table II). In the group of patients the mean maximum systolic pressure, in four cystometries, decreased $(p=0.003)$ from $147 \mathrm{mmHg}$ (range 119165 , SD 14) to $118 \mathrm{mmHg}$ (range 99-145, SD 14). The mean maximum diastolic pressure also decreased significantly $(p=0.003)$ 
Table II Data regarding blood pressure $(\mathrm{BP}, \mathrm{mmHg})$, heart rate $(\mathrm{HR})$ and detrusor pressure. Each figure represents the mean of four observed values (four consecutive cystometries before and after nifedipine respectively). The right column gives the mean values of the group and the statistical significance of the differences between pre- and post-nifedipine values

\begin{tabular}{|c|c|c|c|c|c|c|c|c|c|c|c|}
\hline & \multicolumn{11}{|c|}{ Patients } \\
\hline & 1 & 2 & 3 & 4 & 5 & 6 & 7 & 8 & 9 & 10 & Mean \\
\hline \multicolumn{12}{|c|}{ Systolic baseline BP } \\
\hline Pre nifedipine & 106 & 94 & 108 & 118 & 113 & 108 & 120 & 125 & 120 & 118 & 113 \\
\hline Post nifedipine & 98 & 87 & 103 & 105 & 111 & 99 & 98 & 80 & 108 & 104 & $\begin{array}{c}99 \\
p=0.003\end{array}$ \\
\hline \multicolumn{12}{|c|}{ Diastolic baseline BP } \\
\hline Pre nifedipine & 65 & 60 & 79 & 79 & 69 & 69 & 84 & 85 & 88 & 83 & 76 \\
\hline Post nifedipine & 66 & 62 & 76 & 68 & 70 & 55 & 63 & 56 & 76 & 75 & $\begin{array}{c}67 \\
p=0.014\end{array}$ \\
\hline \multicolumn{12}{|c|}{ Systolic maximum BP } \\
\hline Pre nifedipine & 144 & 119 & 149 & 165 & 140 & 143 & 165 & 158 & 143 & 144 & 147 \\
\hline Post nifedipine & 131 & 99 & 124 & 145 & 121 & 124 & 100 & 115 & 110 & 115 & $\begin{array}{l}118 \\
p=0.003\end{array}$ \\
\hline \multirow{2}{*}{\multicolumn{12}{|c|}{$\begin{array}{l}\text { Diastolic maximum BP } \\
\text { Pre nifedipine }\end{array}$}} \\
\hline Pre nifedipine & 105 & & & & & & & & & & \\
\hline Post nifedipine & 95 & 76 & 99 & 93 & 81 & 71 & 75 & 71 & 89 & 81 & $\begin{array}{c}83 \\
p=0.003\end{array}$ \\
\hline \multicolumn{12}{|c|}{ Systolic BP reaction } \\
\hline Pre nifedipine & 38 & 25 & 41 & 48 & 28 & 35 & 45 & 33 & 23 & 26 & 34 \\
\hline Post nifedipine & 34 & 12 & 21 & 40 & 10 & 25 & 3 & 35 & 3 & 11 & $\begin{array}{c}19 \\
p=0.003\end{array}$ \\
\hline \multicolumn{12}{|c|}{ Diastolic BP reaction } \\
\hline Pre nifedipine & 40 & 42 & 45 & 38 & 28 & 32 & 35 & 35 & 28 & 19 & 34 \\
\hline Post nifedipine & 30 & 15 & 23 & 25 & 11 & 16 & 13 & 15 & 13 & 6 & $\begin{array}{c}17 \\
p=0.003\end{array}$ \\
\hline \multicolumn{12}{|c|}{ Baseline HR (beats/min) } \\
\hline Pre nifedipine & 60 & 67 & 57 & 57 & 61 & 59 & 60 & 69 & 73 & 64 & 63 \\
\hline Post nifedipine & 67 & 77 & 59 & 76 & 62 & 65 & 64 & 73 & 64 & 74 & $\begin{array}{c}68 \\
p=0.012\end{array}$ \\
\hline
\end{tabular}


from $110 \mathrm{mmHg}$ (range 96-124, SD 10) to $83 \mathrm{mmHg}$ (range 71-99, SD 10). The blood pressures in each cystometry are illustrated in Figure 1, which also shows that there was a significant decrease in all four cystometries that were performed after the medication compared to the mean values of the four cystometries before medication. The end of the last cystometry was 64-100 (median 82) min after the administration of nifedipine. The decrease of the maximum blood pressure was due to both a significant decrease of the systolic $(p=0.003)$ and diastolic $(p=0.014)$ baseline blood pressure and a significant decrease of the systolic $(p=0.003)$ and diastolic $(p=0.003)$ blood pressure reaction during cystometry. The data of the individual patients are given in Table II.

\section{Heart rate}

The mean baseline heart rate (before filling of bladder) was 63 (range 57-73, SD 5.2) beats/min and increased after nifedipine to 68 (range 59-77, SD 6.2) beats/min. This difference was statistically significant $(p=0.012)$, and an increase was observed in all but one patient (Table II).

\section{Detrusor pressure}

In the group of patients the mean maximum detrusor pressure, in four cystometries, decreased from $9.8 \mathrm{kPa}$ (range 5.5-14.5, SD 3.1 ) to $8.4 \mathrm{kPa}$ (range $5.5-11.8$, SD 2.2) after nifedipine. This difference was statistically significant $(p=0.025)$. As shown in Table II, however, a decrease was not observed in all patients and in some it was minimal.

The mean (mean of four cystometries) time during which the detrusor pressure exceeded $4 \mathrm{kPa}$ decreased from $151 \mathrm{~s}$ (range 9-358, SD 113) to $93 \mathrm{~s}$ (range 5-234, SD 79). This difference was also statistically significant $(p=0.046)$, but not observed in all patients (Table II).

The mean (mean of four cystometries) time during which the detrusor pressure exceeded $2 \mathrm{kPa}$ (duration of contraction) decreased from $223 \mathrm{~s}$ (range 45-401, SD 122) to $171 \mathrm{~s}$ (range $39-359, \mathrm{SD} 90$ ). This 


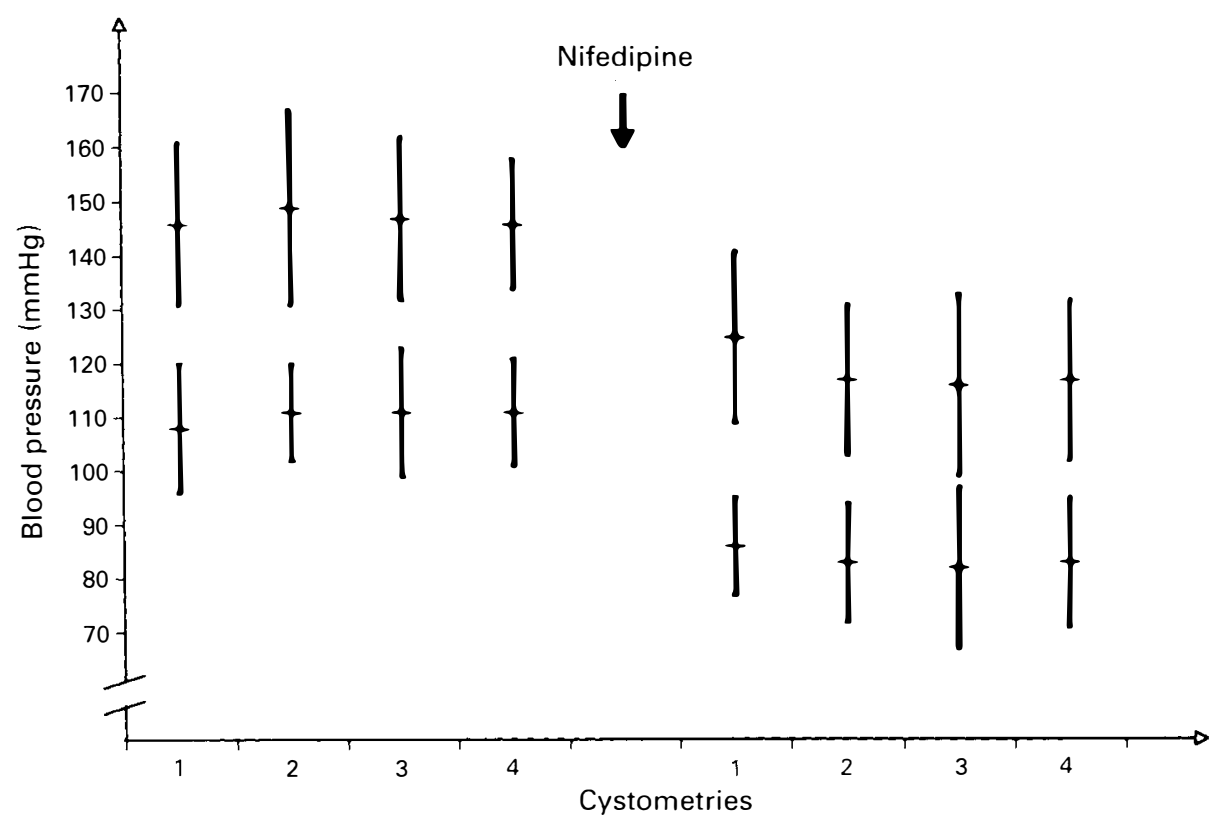

Figure 1 Maximum systolic and diastolic blood pressure in four cystometries before and after administration of nifedipine. Each bar shows the mean value and the standard deviation in the group of patients $(n=10)$.

difference was not statistically significant $(p=0.07)$.

\section{Symptoms}

Two patients reported a feeling of sweating in their necks and faces and a 'feeling of intracranial pressure', during the emptying phases before nifedipine. The feeling of intracranial pressure was specified by both patients as something like a headache but less severe. Both symptoms disappeared in one of the patients and the feeling of sweating disappeared in the other, with nifedipine.

After administration of nifedipine one patient reported a warm feeling in his face.

\section{Discussion}

After administration of nifedipine, the maximum blood pressure during cystometry decreased in all patients. In a previous study we found a correlation between the blood pressure increase and the duration of the detrusor pressure elevation. ${ }^{5}$ In the present study, the maximum detrusor pressure or the time during which the detrusor pressure exceeded $4 \mathrm{kPa}$ decreased after nifedipine in most of the patients. Hence, it seems that, at least in some patients, the cause of the weaker blood pressure reaction might be a combination of a direct vasodilator effect of nifedipine ${ }^{8}$ and an indirect effect via relaxation of smooth muscles of the urinary bladder and urethra. ${ }^{9}$ Our results support the observation by Lindan et $a l^{2}$ and Dykstra $e a^{3}$ that calcium channel blockers are effective against reflex elevation of blood pressure in patients with a high level spinal cord injury.

After sublingual administration of nifedipine the plasma concentration is maximal after 30 min. ${ }^{10}$ The vasodilator effect in essential hypertension ${ }^{11}$ and in healthy subjects $^{12}$ is closely correlated with the plasma levels. Further studies would be needed in order to predict the extent of the hypotensive effect of the drug in patients with a spinal cord injury. ${ }^{5}$ In those clinical situations where reflex hypertension is a severe problem the stimulus probably is stronger 
and of longer duration than in this study. On the other hand the stimulus can also elicit a short and moderate hypertensive response compared to the dose of nifedipine. A resulting prolonged hypotensive period would be difficult to tolerate for the patients, especially when there is already a neurogenic hypotension with poor compensatory vasomotor mechanisms.

Therefore, to cope with the paroxysmal hypertension, eg during cystoscopy, ${ }^{3}$ on one hand, and the adverse effects of nifedipine $e^{2,5,13,14}$ on the other hand, it is necessary to determine the dosage on an individual basis.

\section{Conclusions}

Nifedipine has a prophylactic effect on reflex elevation of the blood pressure in spinal cord injured patients with autonomic dysreflexia. The medication can be given a short time before an anticipated attack and the duration of the effect seems to be long enough to be useful, eg in cystoscopy and other diagnostic or therapeutic procedures.

\section{References}

1 Guttmann L, Whitteridge D (1947) Effects of bladder distension on autonomic mechanisms after spinal cord injuries. Brain 70: $361-404$.

2 Lindan R, Leffler EJ, Kedia KR (1985) A comparison of the efficacy of an alpha-I-adrenergic blocker and a slow calcium channel blocker in the control of autonomic dysreflexia. Paraplegia 23: 34-38.

3 Dykstra DD, Sidi AA, Anderson LC (1987) The effect of nifedipine on cystoscopy-induced autonomic hyperreflexia in patients with high spinal cord injuries. J Urol 138: 1155-1157.

4 VerVoort SM, Donovan WH, Dykstra DD, Syers P (1988) Increased current delivery and sperm collection using nifedipine during electroejaculation in men with high spinal cord injuries. Arch Phys Med Rehabil 69: 595-597.

5 Thyberg M, Ertzgaard P, Gylling M, Granerus G (1992) Blood pressure response to detrusor pressure elevation in patients with a reflex urinary bladder after a cervical or high thoracic spinal cord injury. Scand J Rehabil Med 24: 187-193.

6 Thyberg M, Gedda S, Johansen PB, Lassvik C, Spångberg A, Engberg A (1989) Continuous monitoring of detrusor pressure in patients with a reflex urinary bladder after spinal cord injury. Scand J Rehabil Med 21: $115-121$.

7 Thyberg M, Spångberg A, Lassvik C (1990) Detrusor pressure in cystometry compared to physiological filling in patients with a reflex urinary bladder after spinal cord injury. Scand J Rehabil Med 22: 145-150.

8 Bartorelli C, Magrini F, Moruzzi P, Olivari MT, Polese A, Fiorentini C et al (1978) Haemodynamic effects of calcium antagonist agent (nifedipine) in hypertension-therapeutic implications. Clin Sci Mol Med 55: 4: 291s-292s.

9 Forman A, Andersson K, Henriksson L, Rud T, Ulmsten U (1978) Effects of nifedipine on the smooth muscle of the human urinary tract in vitro and in vivo. Acta Pharmacol Toxicol 43: 111-118.

10 Hoyo-Vadillo C, Castaneda-Hernández G, Herrera JE, Vidal-Gárate J, Salazar LA, Moreno-Ramos A et al (1989) Pharmacokinetics of oral nifedipine-relevance of the distribution phase. J Clin Pharmacol 29: 251-256.

11 Aoki K, Sato K, Kawaguchi Y, Yamamoto M (1982) Acute and longterm hypotensive effects and plasma concentrations of nifedipine in patients with essential hypertension. Eur J Clin Pharmacol 23: 197-201.

12 Kleinbloesem CH, Van Brummelen P, Van de Linde JA, Voogd PJ, Breimer DD (1984) Nifedipinekinetics and dynamics in healthy subjects. Clin Pharmacol Ther 35: 742-749.

13 Shettigar UR, Loungani R (1989) Adverse effects of sublingual nifedipine in acute myocardial infarction. Crit Care Med 17: 196-197.

14 Boden WE, Korr KS, Bough EW (1985) Nifedipine-induced hypotension and myocardial ischemia in refractory angina pectoris. JAMA 253: $1131-1135$. 